\title{
Prática de cuidar/cuidado aos portadores de transtornos mentais: concepção dos enfermeiros
}

\author{
Practice of care/caring for patients with mental disorders: perception of nurses
}

\author{
Fabiana Dias Lima Vidal ${ }^{1}$, Verbena Santos Araújo², Elisângela Braga de Azevedo ${ }^{3}$ \\ Edmundo de Oliveira Gaudêncio ${ }^{4}$, Maria Djair Dias ${ }^{5}$, Maria de Oliveira Ferreira Filha ${ }^{6}$
}

\begin{abstract}
RESUMO
Objetivo: Conhecer a concepção dos Enfermeiros dos Centros de Atenção Psicossocial (CAPS) acerca do cuidar/cuidado de portadores de transtornos mentais e analisar as especificidades do cuidar/cuidado praticado.

Materiais e Métodos: Estudo empírico, de caráter qualitativo, constituído a partir das falas de sete enfermeiros vinculados aos CAPS, coletadas através de entrevista semiestruturada, tendo como técnica a análise de conteúdo.

Resultados: Desenharam-se quatro categorias: Cuidar/cuidado como atenção às necessidades do ser; Cuidar/cuidado como forma diferenciada/indiferenciada de cuidado; Cuidar/cuidado como reinserção social, respeito e atenção; Cuidar/cuidado como relacionamento difícil.

Conclusão: Constatou-se que os enfermeiros mostram-se conscientizados do cuidar direcionado aos portadores de transtornos mentais e têm alcançado resultados surpreendentes, norteando seus limites e avanços na reabilitação e que o cuidar deve ser entendido e praticado de forma integral, humanizada e interdisciplinar.
\end{abstract}

Palavras-chave: enfermagem; sofrimento psíquico; saúde mental.

\begin{abstract}
Objective: To learn about the concepts of the Psychosocial Care Centers (CAPS) nurses about the care/care of patients with mental disorders and to analyze the specific characteristics of care/care practiced.

Materials and Methods: Empirical study, of a qualitative nature, composed from the discourse of seven nurses coupled to the CAPS, collected through semi-structured interview, using the content analysis technique.

Results: Four categories were made: Care/caring as an attention to the human being needs; Care/caring as differentiated/undifferentiated care form; Care/caring as social reintegration, respect and care; Care/caring as a difficult relationship.

Conclusion: We have found that the nurses are aware of the care directed to the mental disorder individuals and have achieved remarkable results, guiding their limits and advances in rehabilitation and that caring should be understood and practiced in an integral, humanized and interdisciplinary way.
\end{abstract}

Keywords: nursing; psychological distress; mental health.

\footnotetext{
${ }^{1}$ Enfermeira. Especialista em Auditoria em Saúde, UNIMED, Campina Grande (PB), Brasil.

${ }^{2}$ Enfermeira. Doutoranda em Enfermagem pelo Programa de Pós-Graduação em Enfermagem da Universidade Federal da Paraíba (UFPB), João Pessoa (PB), Brasil.

${ }^{3}$ Enfermeira. Doutoranda em Enfermagem pelo Programa de Pós-Graduação da UFPB. Professora do Departamento de Enfermagem da Faculdade de Ciências Médicas de Campina Grande.

${ }^{4}$ Médico Psiquiatra. Doutor em Sociologia pela Universidade Federal de Campina Grande. Professor Adjunto IV da Universidade Federal de Campina Grande e Titular da Universidade Estadual da Paraíba Campina Grande (PB), Brasil.

${ }^{5}$ Enfermeira. Doutora em Enfermagem. Professora Associado I do Programa de Pós-Graduação em Enfermagem da UFPB, João Pessoa (PB), Brasil.

${ }^{6}$ Enfermeira. Doutora em Enfermagem pela Universidade Federal do Ceará, Professora Associado II do Programa de Pós-Graduação em Enfermagem da UFPB, João Pessoa (PB), Brasil.
} 


\section{INTRODUÇÃO}

A palavra cuidar origina-se do Latim cogitare pensar, e é definido como "aplicar a atenção a", "tratar", "interessar-se por" . O cuidar faz parte das necessidades básicas para a sobrevivência da vida humana: o cuidar de si, o cuidar do outro e o ser cuidado $^{2}$. Contudo, o cuidado é imprescindível para desenvolver a dimensão humana. Significa conceder direito de cidadania à nossa capacidade de sentir o outro; ter compaixão por todas as pessoas que sofrem; obedecer mais à lógica do coração, da cordialidade e da gentileza do que à da conquista e do uso utilitário das coisas $^{3}$

O cuidar é visto, então, como o ideal ético da Enfermagem, incidindo de esforços no sentido de proteger, promover e preservar, ajudando o outro a encontrar sentido na doença, sofrimento e dor, bem como na própria existência. Embora compreendido como elemento central para a prática profissional da Enfermagem, não lhe é particular, pois o mesmo remonta à origem da humanidade. Nesse contexto, o cuidado exige técnicas e habilidades e é nesse campo, que o cuidado da Enfermagem é praticado na área da saúde mental, sendo esse, nosso foco, neste estudo.

Quando se discute saúde mental é necessário referir os modelos atuais de cuidado, bem como, os contextos históricos, políticos, sociais e culturais e suas concepções sobre "loucura", do modelo hospitalocêntrico datado do século XVIII até os movimentos em torno da Reforma Psiquiátrica, em meados da década de 1960 do século passado, buscando-se compreender sua complexidade, no que concerne ao modo humanitário de abordar a doença mental, inspirado a partir do modelo Italiano.

$\mathrm{Na}$ década de 1980 do século XX, a busca pela transformação da saúde mental começa a ser uma realidade na política de saúde pública brasileira, na qual a luta por reforma no âmbito da saúde mental não se deu de modo desvinculado da luta pela reforma sanitária. Em 1987, como desdobramento da VIII Conferência Nacional de Saúde, realizaram-se dois eventos que marcaram o movimento em prol da transformação da assistência em saúde mental brasileira: a I Conferência Nacional de Saúde Mental e o
II Encontro Nacional de Trabalhadores em Saúde Mental, culminando com o que se almejou chamar de Reforma Psiquiátrica Brasileira ${ }^{4}$.

Em 1991, foi aprovado pelo Congresso Nacional o Projeto de Lei no. 3.657/91 de autoria do Deputado Paulo Delgado que dispõe sobre a extinção progressiva dos manicômios e sua substituição por novas modalidades de atendimento, tais como: hospitais-dia, Centros de Atenção Psicossocial - CAPS - e Núcleos de Atenção Psicossocial - NAPS, enquanto regulamentam as internações psiquiátricas compulsórias, tudo isso culminando na Lei no. 10.216/01, que dispõe sobre os direitos do portador de transtorno mental, tornando-se um marco na história da psiquiatria brasileira, por envolver, em tal proposta, profissionais da área de saúde, usuários e familiares ${ }^{5}$.

Por outro lado, normatizando o processo de criação dos CAPS, no Brasil, em 2004, o Ministério da Saúde definiu-os como um serviço de saúde e comunitário do SUS e como um lugar de referência e tratamento para pessoas que sofrem com transtornos mentais ${ }^{5}$.

Tais serviços são ambientes abertos de tratamento que propiciam o máximo de aproximação dos espaços onde os indivíduos costumam viver, casa, trabalho, escola, para que sua reinserção social e seu retorno ao convívio em comunidade se deem sem maiores dificuldades. São, portanto, estruturas abertas de tratamento que, em tese, se propõem a desmontar o tradicional sistema manicomial e romper com os limites e a inércia habitual dessas instituições ${ }^{5}$.

De acordo com a proposta do CAPS, faz-se necessário pensar os cuidados da Enfermagem para com os usuários dos serviços de saúde mental em uma proposta interdisciplinar e integral. Para tanto, o enfermeiro tem um grande desafio enquanto integrante das equipes que atuam nesses serviços substitutivos da reforma psiquiátrica.

Além disso, percebe-se a importância do papel da Enfermagem, assim como, dos demais membros da equipe na manutenção de um ambiente que favoreça esse tratamento: um ambiente de liberdade, de acolhimento, de respeito às pessoas e às leis da comunidade, de estímulo às habilidades $e$ às capacidades desses profissionais de atuar na área da 
saúde mental, um campo que, embora os diversos avanços ainda se encontram em expansão.

Assim, este estudo nos remete aos seguintes questionamentos: como os enfermeiros dos CAPS cuidam dos portadores de transtornos mentais? Quais as especificidades do cuidado praticado pelos enfermeiros dos CAPS?

Desta forma, esse trabalho teve como objetivo conhecer a concepção dos Enfermeiros dos CAPS acerca do cuidar/cuidado oferecido aos portadores de transtornos mentais e analisar as especificidades do cuidar/cuidado praticado pelos Enfermeiros nos CAPS.

\section{MATERIAIS E MÉTODOS}

O presente estudo foi delineado espelhando-se nos estudos descritivo, exploratório e qualitativo, predominando as premissas da entrevista oral, condição que consideramos importante para consecução dos objetivos propostos. Para a produção do material empírico foi adotado um instrumento contendo questões subjetivas, assim descritas: $O$ que significa 0 cuidar/cuidado do Enfermeiro? Como você cuida do usuário com transtorno psíquico? Como deve ser o cuidado do usuário com transtorno psíquico? Quais as dificuldades e/ou facilidades no cuidado do Enfermeiro no usuário com transtorno psíquico?

A pesquisa foi realizada nos sete CAPS do município de Campina Grande-PB. Fizeram parte do estudo sete enfermeiros, sendo selecionados através de amostra aleatória, um enfermeiro de cada serviço. O critério de inclusão considerado na pesquisa foi: que os sujeitos tivessem pelo menos um ano de atuação no serviço; tivessem vínculo empregatício com o serviço, e aceitassem participar da pesquisa, pois, dessa forma, teriam um maior tempo de vivência junto aos usuários para que pudessem responder aos questionamentos com maior propriedade. Desse modo, nenhum enfermeiro convidado se recusou em participar da pesquisa.

O material empírico foi produzido por meio de entrevistas as quais foram agendadas e realizadas individualmente no mês de agosto de 2008, após a assinatura do Termo de Consentimento Livre e Esclarecido, sendo observada a privacidade do respondente. Todas as entrevistas foram gravadas e transcritas na íntegra.

O material empírico foi analisado com base na análise de conteúdo, tipo categorial temática proposta por Bardin $^{6}$. Desse modo, foi realizada a transcrição das entrevistas em sua literalidade e os resultados encontrados foram estruturados em categorias temáticas, que permitiu compreender criticamente o sentido das falas e descobrir elementos ocultos, indo além das aparências do que está sendo comunicado. $\mathrm{Na}$ apresentação dos resultados utilizou-se à técnica da narrativa, que possibilitou à confrontação de significados a luz da literatura pertinente ao tema em estudo.

Em respeito à Resolução ํo 196/96 do Conselho Nacional de Saúde, o projeto foi submetido à análise do Comitê de Ética em Pesquisa da UEPB, tendo sido aprovado sob o protocolo CAAE nº 0158.0.133.000-08.

\section{RESULTADOS}

Através da análise do material empírico contidas nas falas dos enfermeiros entrevistados, construíram-se categorias temáticas nas quais foram descritas a seguir:

O Cuidar/Cuidado como atenção às necessidades do Ser

É ter um olhar voltado para as necessidades do ser cuidado de forma integral e humanizada. (D1)

Cuidar em saúde mental significa dar assistência integral ao usuário, sem discriminação, com ética, respeitando as diferenças. (D2)

O cuidar em enfermagem significa ver o ser humano como um ser único, em todos os aspectos, seja de ordem biológica, psíquica e social, pois, apesar de vivermos em um imenso planeta, cada ser tem sua singularidade e o cuidado deve ser único para cada paciente. (D5)

Estar habituado a amparar, prestar auxílio ao indivíduo, seja no momento necessário o qual ele necessite (...) cuidar esse que presta uma assistência de forma qualificada, humanizada e dedicada. (D6)

Os entrevistados revelam que ao prestar cuidado, o enfermeiro estar convencido de que tal cuidado e sua 
forma de cuidar são fundamentais para que os usuários sejam atendidos de forma equânime, integral e humanizada. Para os entrevistados, é necessário que na interação enfermeiro e usuários, o respeito pelas diferenças, à singularidade e a subjetividade sejam priorizadas, para que o cuidado oferecido seja qualificado e ético. Desse modo, cabe ao enfermeiro, observar suas atitudes de modo que seu trabalho tenha significância e qualidade, seja na recuperação do usuário ou no âmbito da equipe com quem se relaciona no cotidiano.

Isso posto, pode-se afirmar que perceber o outro requer uma atitude profundamente humana. Reconhecer e promover a humanização à luz de considerações éticas demanda o adequado esforço para rever atitudes e comportamentos, principalmente no que se refere ou diz respeito aos profissionais envolvidos direta e indiretamente no cuidado à pessoa com transtorno mental.

\section{O Cuidar/Cuidado como forma diferenciada/} indiferenciada de Cuidado.

As falas abaixo remetem para a formação dessa categoria:

[...] Sim, no caso do paciente psiquiátrico, não existe uma forma diferenciada, apenas um cuidado mais amplo, quando há presença de crise. (D1)

O cuidado do portador de transtorno mental não deve ser diferente de outros pacientes. Eu cuido da mesma forma dos outros, sem discriminação, nem receio. (D2)

O indivíduo portador de transtorno mental nada mais é que um ser humano igual a todos os outros. (D5)

Olha o cuidado deve ser com respeito e muita atenção às suas necessidades. Quando o paciente psiquiátrico é tratado de forma humanizada sua recuperação e adesão ao tratamento evolui muito bem. (D3)

Os entrevistados não fazem diferenciação quanto ao cuidar que oferecem ao portador de transtorno mental, enfocando a importância do não preconceito, porém, um entrevistado nos revela que, o que muda é a forma como é expresso o cuidado, revelando que, quando existe uma ação de humanização estabelecida com o usuário, sua recuperação e sua adesão ao tratamento tornam-se bem mais eficazes. Desse modo, constata-se que o cuidar configura-se um atributo típico de todos os profissionais de saúde e, em especial, do enfermeiro, uma vez que, em sua gênese, esse se torna tanto uma matéria técnica, quanto humanística.

O Cuidar/Cuidado como ressocialização, respeito e atenção.

No cuidado existem um compromisso e uma responsabilidade em "estar-no-mundo", objetivando não apenas fazer aquilo que satisfaz, mas ajudar a construir uma sociedade com base em princípios éticos. Nossos entrevistados relatam:

Nós, como funcionários da saúde mental, trabalhamos com o paciente psiquiátrico a fim de ressocializá-lo na comunidade. (D1)

Particularmente, aqui no CAPS, eu acredito que, quanto mais cedo, as crianças, principalmente, forem acolhidas e tratadas, mais chances têm de não ter a primeira crise e consequentemente serem internadas, ficando também mais fácil inseri-las na sociedade. (D5)

Visualiza-se, nas entrelinhas das falas citadas, que a ressocialização e a inclusão social tornou-se uma meta fim para os enfermeiros que atuam nos CAPS. Isto a partir da intervenção precoce, para que esses não venham a desenvolver uma crise por déficit na assistência. Para isso, o respeito, a ética e a solidariedade, são fatores essenciais, desse modo, os sujeitos com limitações são inseridos nos afazeres cotidianos, possibilitando, assim, autonomia para a vida na comunidade.

O Cuidar/Cuidado como relacionamento difícil.

Sob essa categoria, observa-se as falas dos entrevistados:

A falta de compromisso da família do usuário para o controle de medicação e acompanhamento do mesmo. (D1)

Não adesão da família ao tratamento do usuário. (D2) 
[...] sim, [quando] os usuários em crise quebram objetos. É difícil. (D1)

Em determinados momentos, nos quadros de desorientação, crises ou surtos, agressividades. (D6)

Diante das situações relatadas pelos enfermeiros, o cuidar/cuidado ao portador de transtorno mental, em alguns momentos, representa um relacionamento difícil, principalmente nos momentos de crise/surtos, em que, os usuários, muitas vezes, tornam-se agressivos, como também podemos perceber nos discursos que a família não tem contribuído com o tratamento proposto, fragilizando também a relação estabelecida entre o enfermeiro e o usuário.

Faz-se necessário lembrar, a importância da reflexão e ação, teoria e prática para se poder conhecer a forma de cuidar como meio transformador do simples cuidado em terapêutica maior. Isso, porém, exige um projeto terapêutico, por parte do Enfermeiro, sobretudo junto ao portador de transtornos mentais, objetivando a humanização de uma forma curativista e segregadora de cuidar que, durante séculos, desconsiderou o louco como um cidadão.

\section{DISCUSSÃO}

A arte do cuidar em Enfermagem é, sobretudo, a capacidade de reconhecer a expressão dos sentimentos dos seres humanos. Cuidar é, então, uma forma de criar, uma possibilidade de intervir e transformar as situações. Assim, a presença do enfermeiro faz-se essencial nesses momentos.

Foi sobre isso que falaram os entrevistados. O cuidar faz parte da gênese do ser enfermeiro. Para a superação das dificuldades impostas pela doença do portador de transtorno mental, é necessário que haja, concomitantemente, o ato de cuidar. Esse cuidar deve ser entendido e praticado de forma integral, humanizada e interdisciplinar, isto é, pensando-se não somente nas dificuldades apresentadas e inerentes ao próprio cuidar, mas no indivíduo que apresenta sofrimento psíquico, seja ele psiquiátrico ou não.

Assim, as ações de Enfermagem acontecem numa relação compartilhada, baseada nas necessidades de interação e na convivência com os outros e com o ambiente de cuidado, em que, muitas vezes, determinadas necessidades, tais como o simples fato de comunicar-se com familiares, podem ser facilitadas ou dificultadas pelo enfermeiro. Assim, é priorizada a importância da enfermagem como fundamental para a humanização da assistência, devendo ser implementadas ações de integralidade e interdisciplinares, permitindo 0 desenvolvimento de competência dos que a desenvolvem ${ }^{7}$.

Apesar de a enfermagem no passado possuir uma formação predominantemente baseada no atendimento às obrigações técnicas e biológicas do indivíduo, na atualidade esta assistência dá-se no sentido de suprir não somente tais necessidades, mas também contemplar os desejos, anseios e medos do paciente, aceitando-se que essas necessidades estão presentes em qualquer usuário, seja ele psiquiátrico ou não.

Complementando a análise dos discursos explicitados, no item intitulado "Resultados", evidenciase, neste estudo, que, na área da saúde, para o profissional cuidar do outro, cuidar do ser e promover saúde é preciso ver o ser humano de forma completa e integral e com isso, o profissional deve promover uma relação com os outros e com o mundo. Não se pode ver o usuário de forma particionada, fragmentada. É nessa perspectiva, que o cuidar do outro não pode ser somente o exercício de uma técnica pronta, inabalável e absoluta, ou seja, técnica dissociada do aspecto humano em que deve estar entremeado o ato de cuidar. Ter o domínio dela é fundamental, mas a técnica deve ser completada pela sensibilidade, pela ética, pelo respeito, pelo amor e por uma aceitação e compreensão do outro em todas as suas especificidades ${ }^{8}$.

Por sua vez, a atividade cuidadora do enfermeiro exige habilidade para com a comunicação nas suas mais variadas formas, como o toque, a percepção atenta, a escuta, além do interesse pelo ser cuidado, como forma de desvelar o saber que está posto na Enfermagem, objetivando a solidariedade para com a satisfação de necessidades imediatas ou mediatas, na prevenção de males futuros, quer individual ou familiar.

Desse modo, ao prestar cuidado, o enfermeiro deve estar convencido de que a forma em que ele utiliza para dar assistência ao usuário deve estar pautada também 
na organização e ética. Nesse sentido, seu trabalho terá significância e qualidade na recuperação do usuário, no âmbito da equipe com quem se relaciona no cotidiano ${ }^{7}$.

Tal premissa nos faz acreditar que o cuidar/cuidado não pode ser ministrado de modo diferente para diferentes indivíduos, sobretudo, deve ser equânime, em função da diversidade de necessidades pessoais.

Neste contexto, faz-se necessário reconhecer que todo usuário traz consigo suas limitações, suas subjetividades, suas dependências, suas dimensões sociais e psicológicas. Ouvi-lo pode também proporcionar maior motivação e satisfação, inclusive não só para o usuário, mas, também, para o profissional prestador do cuidado, ao tomar conhecimento de sua real contribuição para com o benefício daqueles de quem ele cuida e das instituições de saúde onde trabalha, conferindo-Ihe enriquecimento individual e profissional de qualidades, como também acúmulo de experiência.

Portanto, a relação enfermeiro-usuário se dá na interação entre duas ou mais pessoas, entre o profissional e o usuário que necessita de ajuda e/ou seus familiares, e se estabelece com a finalidade melhorar a condição de saúde do paciente.

Tal relacionamento, complexo, envolve as necessidades bio-psico-sócio-espirituais e afetivas do paciente e está diretamente relacionado com o processo de comunicação estabelecido entre os envolvidos no processo. Portanto, para haver o cuidado eficiente $e$ eficaz, fruto desse relacionamento, ambos os sujeitos precisam compreender os sinais presentes na relação interpessoal, seja pelos gestos, expressões ou palavras ${ }^{9}$.

Contudo, as barreiras que provocam um relacionamento difícil entre a equipe de cuidadores e o paciente, na realização do cuidado na forma idealizada, citam-se: o conflito de valores na profissão; a falta de um forte sentido de self por parte de cuidadores; a ausência de uma ética específica, menos dependente da ética e das decisões médicas; a falta de conhecimento; o tempo limitado para atualização e reflexão, devido ao excesso de responsabilidades; a carência de apoio para a prática do cuidado e desatenção ao processo de socialização ${ }^{10}$.
Para isso, alguns estudos evidenciam que os enfermeiros sentem dificuldade para realizar cuidado à pessoa em sofrimento psíquico e que isso deriva do déficit de preparo na formação profissional, muitos mostram insegurança e relacionam este sentimento à escassez de conteúdo e carga horária insuficiente na graduação, impossibilitando, desta forma, um contato maior com pessoas em situação de sofrimento psíquico durante as práticas curriculares. Porém, é notório os avanços na atualidade, diante os progressos na reforma psiquiátrica, na disciplina de saúde mental, uma vez que, este começa a ser reconhecida como essencial na formação dos profissionais da enfermagem, que necessitam aprender a usar os conhecimentos que embasam a compreensão do ser humano, das motivações e comportamentos, bem como interagir com o usuário no momento crítico de sofrimento mental ${ }^{11,12}$.

Estar empossado de saúde mental implica capacidade, por parte de cada ser humano, em se adaptar ao ambiente em que se relaciona e do qual participa ou pode contribuir de forma construtiva nas modificações possíveis de seu ambiente físico e social. A atuação do enfermeiro junto aos portadores de transtorno mentais requer muito mais que a simples compreensão clínica da doença mental ou das crises pessoais e/ou familiares por ela suscitadas ou, ainda, da adesão ou não dos familiares ao tratamento.

No cuidar/cuidado, diante das situações relatadas pelos enfermeiros, faz-se necessário lembrar a importância da reflexão e ação, teoria e prática para poder conhecer a forma de cuidar como meio transformador do simples cuidado em terapêutica maior. Isso, porém, exige um projeto terapêutico, por parte da Enfermagem, sobretudo junto ao paciente portador de transtornos mentais, objetivando a humanização de uma forma médica de tratar que, durante séculos, desconsiderou o louco como pessoa.

Isso posto, pode-se afirmar que perceber o outro requer uma atitude que reconheça e promova a humanização, à luz de considerações éticas, demanda o adequado esforço para rever atitudes e comportamentos, principalmente no que se refere aos profissionais envolvidos direta e indiretamente no cuidado à pessoa com transtorno mental. 
Nesse sentido, exponho a compreensão apreendida como direcionadora à proposta do cuidar/cuidado do portador de transtornos mentais, tal como se pode inferir a partir das percepções e das falas de nossos enfermeiros entrevistados: A) O Cuidar e o Cuidado são a própria razão de ser da Enfermagem; B) O Cuidar e o Cuidado exigem a conjugação de conhecimentos, habilidades, experiência, sensibilidade e humanidade no trato daquele de quem se cuida; C) O Cuidar e o Cuidado são os eixos norteadores para um acolhimento de qualidade a ser prestado pelo enfermeiro; D) $O$ Cuidar e o Cuidado estabelecem um desafio constante na relação dialógica entre enfermeiro e usuário, bem como com relação aos demais profissionais da saúde; E) O Cuidar e o Cuidado, prestados de forma integral ao paciente, tanto agem na prevenção de complicações, junto ao usuário, quanto possibilitam para quem dele cuida, satisfação profissional; F) O Cuidar e o Cuidado devem ser praticados de forma interdisciplinar e multirrelacional, de forma que a mutualidade, o trabalho compartilhado, a reciprocidade e a autenticidade tornem-se elementos básicos; G) O Cuidar e o Cuidado, vislumbrados em situação de face a face, possuem a plenitude do encontro, demonstrativo da beleza singular de cada ser, no momento próprio do cuidado.

Este estudo revelou que as ações de Enfermagem acontecem numa relação compartilhada, baseada nas necessidades de interação e na convivência com os outros e com o ambiente de cuidado onde, muitas vezes, determinadas necessidades, tais como o simples fatos de comunicar-se com familiares, podem ser facilitadas ou dificultadas pelo enfermeiro. Assim, o enfermeiro tornou-se um elemento fundamental para a humanização do atendimento oferecido ao portador de transtorno mental, devendo ser implementadas ações de integralidade em termos de trabalho conjunto com outros profissionais do serviço, possibilitando uma assistência ética, integral e humanizada, permitindo, com isso, o desenvolvimento de competência para cuidá-lo.

À guisa destas considerações finais, entendeu-se o quão válido foi enfatizar que este trabalho é apenas uma perspectiva de leitura na percepção do cuidar/cuidado pesquisado, sendo sempre inacabado, servindo como eventual guia aos enfermeiros e profissionais de saúde no sentido de buscar a realidade do cuidado como um diálogo humano constante e criativo. Evidentemente este trabalho não esgota o tema abordado, porque as maneiras de ver e sentir um determinado tipo de cuidar/cuidado são dinâmicas.

Propõem-se avanços em pesquisas e novos estudos, no sentido de desocultar diferentes facetas que sentido dos portadores de transtorno mental sob o olhar do enfermeiro, em particular, e, em sentido geral, de toda e qualquer pessoa, por quaisquer que sejam os profissionais.

Sugere-se, que os resultados deste estudo sejam levados em consideração, a fim de que o profissional enfermeiro possa, meditando sobre o que aqui se fala subsidiar um novo modo de ser e de agir, pois se acredita que tal mudança poderá proporcionar maior e melhor prática de cuidar. Para o caso da Enfermagem, esse Cuidar e esses Cuidados que nos dizem, parafraseando-se o raciocino cartesiano; Cuido, logo existo.

\section{REFERÊNCIAS}

1. Ferreira $A B H$. Novo dicionário da língua portuguesa. $3^{a}$.ed. Curitiba: Positivo; 2004

2. Colliere MF. Promovendo a vida: da prática das mulheres de virtude aos cuidados de enfermagem. Lisboa: Lidel; 1999.

3. Boff L. Saber cuidar: ética do humano. Compaixão pela terra. 16. ed. Petrópolis: Vozes; 2009

4. Oliveira ME. Mais uma nota para a melodia da humanização. In: Oliveira ME, Zampieri MFM, Bruggemann OM. A melodia da humanização: reflexos sobre o cuidado durante o processo do nascimento. Florianópolis: Cidade Futura; 2001. p. 93-99.

5. Brasil. Ministério de Saúde. Saúde mental no SUS: os centros de atenção psicossocial. Brasília (DF): Ministério da Saúde; 2004.

6. Bardin L. Análise de conteúdo. Lisboa: Editora 70; 2009.

7. Castanha ML. A (in)visibilidade da prática de cuidar do ser enfermeiro sob o olhar da equipe de saúde [dissertação]. Curitiba (PR):Universidade Federal do Paraná; 2004. 161f.

8. Martins AA. Antropologia integral e holística: cuidar do ser e a busca de sentido. Bio \& Thikos. 2009; 3(1):87-99.

9. Oriá MOB, Moraes LMP, Victor JF. A comunicação como instrumento do enfermeiro para o cuidado emocional com o cliente hospitalizado. Rev Eletr Enferm [periódico online] 2004;6:292-5. [Acesso em 11 set. 2011]. Disponível em: http://www.fen.ufg.br

10. Waldow VR. Cuidado humano: o resgate necessário. $3^{3}$ ed. Porto Alegre: Saga Luzato; 2001.

11. Maftum MA, Alencastre $M B$. $O$ cenário da qualificação docente de enfermagem em saúde mental no Paraná Nursing. 2008;11(124):404-10. 
12. Brusamarello T, Guimarães AN, Paes MR, Borba LO, Borille DC, Maftum MA. Cuidado de enfermagem em saúde mental ao paciente internado em hospital psiquiátrico. Cogitare Enferm. 2009;14(1):79-84.

\section{Endereço para correspondência:}

Verbena Santos Araújo

Rua José Arimatéia Lima 65, Conjunto dos Professores

Campina Grande/PB.- CEP 58429-065

Telefone: +558388869014

E-mail: verbena.bio.enf@hotmail.com 